\title{
Patient-reported outcome measures in subarachnoid hemorrhage
}

\section{A systematic review}

Edith Nobels-Janssen, MD, * Philip J. van der Wees, PhD, * Wim I.M. Verhagen, MD, PhD, Gert P. Westert, PhD, Ronald H.M.A. Bartels, MD, PhD, and Jeroen D. Boogaarts, MD, PhD

Neurology ${ }^{\circledR}$ 2019;92:1096-1112. doi:10.1212/WNL.0000000000007618
Correspondence Dr. Nobels-Janssen edith.janssen@ radboudumc.nl

\begin{abstract}
Objective

Patient-reported outcomes (PROs) are aspects of a patient's health status and are considered important for stimulating patient-centered care. Current outcome measures in clinical care for patients with aneurysmal subarachnoid hemorrhage (aSAH) are insufficient to capture PROs. In this systematic review, we aimed to summarize the evidence regarding the quality of patientreported outcome measures (PROMs) in aSAH patients.
\end{abstract}

\section{Methods}

We performed a systematic review of the literature published from inception until October 29, 2018, in PubMed, the Cochrane Central Register of Controlled Trials, and EMBASE. Eligible studies had to evaluate measurement properties and capture PROs in aSAH patients. The quality of the studies and measurement properties were assessed using the consensus-based standards for the selection of health status measurement instruments (COSMIN) checklist. The review protocol was registered with PROSPERO (CRD42018058566).

\section{Results}

We identified 9 articles that reported the assessment of 7 different disease-specific and generic PROMs used for aSAH patients, including 5 that focused on the Stroke-Specific Quality of Life Scale (SS-QoL). The methodologic quality of the validation processes used was generally doubtful. None of the PROMs complied with current standards for content validity.

\section{Conclusions}

Due to the low quality of evidence for the measurement properties, the evidence base for selecting a suitable PROM for use with aSAH patients is insufficient. Given the specific longterm consequences of aSAH, we consider a disease-specific PROM the most appropriate, with SS-QoL the most suitable PROM currently available. 


\section{Glossary}

aSAH = aneurysmal subarachnoid hemorrhage; EQ-5D = EuroQol 5D; HUI = Health Utility Index; $\mathbf{m R S}=$ modified Rankin Scale; PRO = patient-reported outcome; PROM = patient-reported outcome measure; QOLIBRI-OS = Quality of Life after Brain Injury overall scale; SAHOT $=$ Subarachnoid Haemorrhage Outcome Tool; SS-QoL = Stroke-Specific Quality of Life scale.

Improvements in treatment strategies in aneurysmal subarachnoid hemorrhage $(\mathrm{aSAH})$ led to a reduction in mortality over the last 30 years, 1,2 meaning that the functional outcome and quality of life of patients with aSAH is becoming increasingly important. ${ }^{1,2}$ Approximately half of patients report persistent problems with memory, mood, or neuropsychological function. ${ }^{3-5}$ These cognitive deficits often go undetected by gross neurologic measures such as the Glasgow Outcome Scale and the modified Rankin Scale (mRS), but can be measured using patient-reported outcome measures (PROMs). ${ }^{4}$ PROMs measure patient-reported outcomes (PROs) and reflect the patient's view of his or her own health status. They are important for improving patient-centered health care and managing the follow-up care of patients. ${ }^{6}$ Although they could be valuable for measuring outcomes that are not represented in clinical outcome measures, PROMs are seldom used in research involving patients with aSAH. ${ }^{7,8}$

In this systematic review, we provide an overview of the available PROMs used in patients with aSAH and review their validity and reliability. This provides an evidence base for the future selection of PROMs in aSAH research and clinical practice, enabling the most effective detection of PROs for patients with aSAH.

\section{Methods}

\section{Search strategy}

The review protocol was registered in the International Prospective Register of Systematic Reviews (PROSPERO) of systematic review protocols (CRD42018058566). ${ }^{9}$ We performed a systematic search of the literature published from inception until October 29, 2018, in PubMed, the Cochrane Central Register of Controlled Trials, and EMBASE. This was done using a 2-step approach: first, a systematic search of the literature was performed from inception until August 15, 2017, and second, the search results were updated monthly to add any potential new studies to the selection. An independent and experienced librarian contributed to the search strategy. To identify studies concerning the measurement properties of PROMs, we searched for validation studies using the keywords "aneurysmal subarachnoid hemorrhage" and "patient-reported outcomes." For the latter, we applied the PROM search filter developed in February 2010 by The PROM Group Oxford at the University of Oxford. ${ }^{10}$ The filter was adjusted and expanded to improve the sensitivity of the search strategy for our target group. In addition, we applied the sensitive search filter developed by Terwee et al. ${ }^{11}$ to identify studies on measurement properties. For the detailed search string used in PubMed, see table 1. The search string was adjusted for use in the other databases. Finally, we performed a reference search of the included full-text articles to identify other relevant studies.

\section{Selection criteria}

Studies were eligible for inclusion if they considered the measurement properties of PROMs in patients with aSAH. The aim of the PROM should be to capture the general aspects of health status, aSAH-related quality of life, or the symptoms associated with aSAH. The PROM needed to have been named to enable its identification. Studies were included if the article was in English, the full text was available, and the results for patients with aSAH were presented separately from any other study population. Editorials and studies concerning children $<18$ years of age or nonhumans were excluded.

\section{Data collection and analysis}

\section{Selection of studies}

Duplicate articles were automatically removed using EndNote X8. Two researchers (E.N.-J. and R.H.M.A.B.) independently reviewed the titles and subsequently the abstracts of the articles. For the included articles, full-text versions were obtained and independently evaluated by the same researchers. In case of disagreement during this process, a third reviewer (P.J.v.d.W.) was asked to adjudicate.

\section{Data analysis}

The studies were analyzed in the 3-step procedure described below.

\section{COSMIN step 1: Quality assessment of the studies}

The assessment of the methodologic quality of the included studies was based on the updated consensus-based standards for the selection of health measurement instruments (COSMIN). ${ }^{12-14}$ This involves a 3-step appraisal of the quality of a PROM: (1) the assessment of the content validity; (2) the appraisal of the internal structure of the questionnaire; and (3) the evaluation of the remaining measurement properties (i.e., reliability, measurement error, criterion validity, and hypotheses testing for construct validity and responsiveness). These steps are allocated in 10 boxes in the COSMIN checklist, each with 3-35 items concerning the methodologic standards for each measurement property. Each item was independently assessed by 2 researchers (E.N.J. and P.J.v.d.W.) using a 4-point rating scale (very good, adequate, doubtful, or inadequate). Finally, an overall score of 
Table 1 PubMed search strategy

\begin{tabular}{|c|c|c|}
\hline Step & Search terms & $\begin{array}{l}\text { No. of studies in } \\
\text { PubMed }\end{array}$ \\
\hline 1 & "Subarachnoid hemorrhage"[MeSH: noexp] & 18,588 \\
\hline 2 & $\begin{array}{l}\text { "Intracranial aneurysm"[MeSH] or intracranial aneurysm[tiab] or intracranial aneurysms } \\
\text { [tiab] or brain aneurysms[tiab] or brain aneurysm[tiab] or cerebral aneurysm[tiab] or } \\
\text { cerebral aneurysms[tiab] }\end{array}$ & 27,877 \\
\hline 3 & “Rupture, spontaneous"[MeSH] or ruptur*[tiab] & 117,188 \\
\hline 4 & Step 2 and step 3 & 8,527 \\
\hline 5 & $\begin{array}{l}\text { Subarachnoid haemorrhage[tiab] or (subarachnoid[tiab] and hemorrhage[tiab]) or } \\
\text { subarachnoid hemorrhage[tiab] or subarachnoid haemorrhages[tiab] or subarachnoid } \\
\text { hemorrhages[tiab] or sah[tiab] or sahs[tiab] or asah[tiab] or subarachnoid hematoma[tiab] } \\
\text { or subarachnoid bleeding[tiab] or subarachnoid bleed[tiab] }\end{array}$ & 24,472 \\
\hline 6 & Step 1 or step 4 or step 5 & 33,127 \\
\hline 7 & "Quality of life"[MeSH] & 150,254 \\
\hline 8 & "Patient reported outcome measures"[MeSH] & 555 \\
\hline 9 & "Patient outcome assessment"[MeSH:noexp] & 3,052 \\
\hline 10 & "Recovery of function"[MeSH] & 40,897 \\
\hline 11 & "Health care surveys"[MeSH] & 29,298 \\
\hline 12 & "Self report"[MeSH] & 18,578 \\
\hline 13 & "Surveys and questionnaires"[MeSH:noexp] & 372,886 \\
\hline 14 & Step 7 or step 8 or step 9 or step 10 or step 11 or step 12 or step 13 & 553,425 \\
\hline 15 & $\begin{array}{l}\text { Recovery of function[tiab] or patient outcome assessment[tiab] or patient outcome } \\
\text { assessments[tiab] or patient-centered outcomes[tiab] or patient-centered outcome[tiab] } \\
\text { or patient centered outcome[tiab] or patient centered outcomes[tiab] or patient reported } \\
\text { outcomes[tiab] or patient reported outcome[tiab] or quality of life[tw] or PROM[tiab] or Qol } \\
\text { [tiab] or hrqol[tiab] or HRQL[tiab] or proms[tiab] or questionnaire[tiab] or questionnaires } \\
\text { [tiab] or scale[tiab] or scales[tiab] or health inde* [tiab] or health indices[tiab] or health } \\
\text { status[tw] or health profile*[tiab] or HRPRO[tiab] or HR-PRO[tiab] or life quality[tw] or QL } \\
\text { [tiab] }\end{array}$ & $1,219,700$ \\
\hline
\end{tabular}

\begin{tabular}{lll}
\hline $\mathbf{1 6}$ & $\begin{array}{l}\text { (patient[tiab] or self[tiab] or carer[tiab] or proxy[tiab]) and (report[tiab] or reported[tiab] or } \\
\text { reporting[tiab] or rated[tiab] or rating[tiab] or ratings[tiab] or based[tiab] or assessed[tiab] } \\
\text { or assessment[tiab] or assessments[tiab]) }\end{array}$ & 1,131,726 \\
\hline $\mathbf{1 7}$ & $\begin{array}{l}\text { (disability[tiab] or function[tiab] or functional[tiab] or functions[tiab] or subjective[tiab] or } \\
\text { utility[tiab] or utilities[tiab] or wellbeing[tiab] or well being[tiab]) and (index[tiab] or indices } \\
\text { [tiab] or measure[tiab] or measures[tiab] or profile[tiab] or profiles[tiab] or score[tiab] or } \\
\text { scores[tiab] or status[tiab]) }\end{array}$ & 621,602 \\
\hline $\mathbf{1 8}$ & Step 14 or step 15 or step 16 or step 17 & $2,694,952$ \\
\hline $\mathbf{1 9}$ & "Psychometrics"[MeSH] & 63,854 \\
\hline $\mathbf{2 0}$ & "Outcome assessment (health care)"[MeSH] & 379,542 \\
\hline $\mathbf{2 1}$ & "Observer variation"[MeSH] & 37,514 \\
\hline $\mathbf{2 2}$ & "Health status indicators"[MeSH] & 237,135 \\
\hline $\mathbf{2 3}$ & "Reproducibility of results"[MeSH] & 338,085 \\
\hline $\mathbf{2 4}$ & "Discriminant analysis"[MeSH] & $\mathbf{8 , 9 8 7}$ \\
\hline $\mathbf{2 5}$ & "Factor analysis, statistical"[MeSH] & 24,018 \\
\hline $\mathbf{2 6}$ & "Minimal clinically important difference"[MeSH] & 19 \\
\hline
\end{tabular}




\begin{tabular}{|c|c|c|}
\hline Step & Search terms & $\begin{array}{l}\text { No. of studies in } \\
\text { PubMed }\end{array}$ \\
\hline 28 & $\begin{array}{l}\text { Instrumentation[sh] or methods[sh] or validation studies[pt] or comparative study[pt] or } \\
\text { psychometr*[tiab] or clinimetr*[tw] or clinometr*[tw] or outcome assessment[tiab] or } \\
\text { outcome measure*[tw] or observer variation[tiab] or reproducib*[tiab] or reliab*[tiab] or } \\
\text { unreliab*[tiab] or valid*[tiab] or coefficient[tiab] or co-efficient[tiab] or homogeneity[tiab] } \\
\text { or homogeneous[tiab] or "internal consistency"[tiab] or agreement[tiab] or precision[tiab] } \\
\text { or imprecision[tiab] or "precise values"[tiab] or test-retest[tiab] or stability[tiab] or } \\
\text { interrater[tiab] or inter-rater[tiab] or intrarater[tiab] or intra-rater[tiab] or intertester[tiab] } \\
\text { or inter-tester[tiab] or intratester[tiab] or intra-tester[tiab] or interobserver[tiab] or inter- } \\
\text { observer[tiab] or intraobserver[tiab] or intra-observer[tiab] or intertechnician[tiab] or } \\
\text { inter-technician[tiab] or intratechnician[tiab] or intra-technician[tiab] or interexaminer } \\
\text { [tiab] or inter-examiner[tiab] or intraexaminer[tiab] or intra-examiner[tiab] or interassay } \\
\text { [tiab] or inter-assay[tiab] or intraassay[tiab] or intra-assay[tiab] or interindividual[tiab] or } \\
\text { inter-individual[tiab] or intraindividual[tiab] or intra-individual[tiab] or interparticipant } \\
\text { [tiab] or inter-participant[tiab] or intraparticipant[tiab] or intra-participant[tiab] or kappa } \\
\text { [tiab] or kappa's[tiab] or kappas[tiab] or repeatab*[tiab] or generaliza*[tiab] or generalisa* } \\
\text { [tiab] or concordance[tiab] or discriminative[tiab] or "known group"[tiab] or factor analysis } \\
\text { [tiab] or factor analyses[tiab] or dimension*[tiab] or subscale*[tiab] or sub-scale*[tiab] or } \\
\text { item discriminant[tiab] or interscale correlation*[tiab] or inter scale correlation*[tiab] or } \\
\text { error[tiab] or errors[tiab] or "individual variability"[tiab] or "standard error of } \\
\text { measurement"[tiab] or sensitiv*[tiab] or responsive*[tiab] or meaningful change[tiab] or } \\
\text { "ceiling effect"[tiab] or "floor effect"[tiab] or "item response model"[tiab] or IRT[tiab] or } \\
\text { Rasch[tiab] or "differential item functioning"[tiab] or DIF[tiab] or "computer adaptive } \\
\text { testing"[tiab] or "item bank"[tiab] or "cross-cultural equivalence"[tiab] }\end{array}$ & $7,456,435$ \\
\hline 29 & Cronbach*[tiab] and (alpha[tiab] or alphas[tiab]) & 17,257 \\
\hline 30 & Item[tiab] and (correlation*[tiab] or selection*[tiab] or reduction*[tiab]) & 16,921 \\
\hline 31 & Test[tiab] and (retest[tiab] or re-test[tiab] & 22,240 \\
\hline 32 & Reliab*[tiab] and (test[tiab] or (retest[tiab] or re-test)) & 73,165 \\
\hline 33 & $\begin{array}{l}\text { (replicab*[tiab] or repeated[tiab]) and (measure[tiab] or measures[tiab] or findings[tiab] or } \\
\text { result[tiab] or results[tiab] or test[tiab] or tests[tiab]) }\end{array}$ & 165,106 \\
\hline 34 & Intraclass[tiab] and correlation*[tiab] & 18,476 \\
\hline 35 & Multitrait[tiab] and scaling[tiab] and (analysis[tiab] or analyses[tiab]) & 134 \\
\hline 36 & Variability[tiab] and (analysis[tiab] or values[tiab]) & 81,461 \\
\hline 37 & Uncertainty[tiab] and (measurement[tiab] or measuring[tiab]) & 6,239 \\
\hline 38 & $\begin{array}{l}\text { (minimal[tiab] or minimally[tiab] or clinical[tiab] or clinically[tiab]) and (important[tiab] or } \\
\text { significant[tiab] or detectable[tiab]) and (change[tiab] or difference[tiab]) }\end{array}$ & 186,806 \\
\hline 39 & Small*[tiab] and (real[tiab] or detectable[tiab]) and (change[tiab] or difference[tiab]) & 6,029 \\
\hline 40 & $\begin{array}{l}\text { Step } 27 \text { or step } 28 \text { or step } 29 \text { or step } 30 \text { or step } 31 \text { or step } 32 \text { or step } 33 \text { or step } 34 \text { or step } 35 \\
\text { or step } 36 \text { or step } 37 \text { or step } 38 \text { or step } 39\end{array}$ & $8,189,416$ \\
\hline 41 & Step 40 and step 18 and step 6 & 3,814 \\
\hline
\end{tabular}

a measurement property was obtained by taking the lowest score for any of the items in that property. ${ }^{12-15}$

\section{COSMIN step 2: Quality assessment of the measurement properties}

The definitions used for the measurement properties are based on the consensus on taxonomy, terminology, and definitions reached by the COSMIN panel. The COSMIN criteria were used to assess whether the results of the measurement properties were sufficient, insufficient, or indeterminate (table 2). ${ }^{13,15,16}$ We reviewed the measurement properties in duplicate (by E.N.-J. and P.J.v.d.W.), and in cases of initial doubt in the final rating, agreement was reached by debate between the 2 reviewers. For the hypotheses testing for construct validity and responsiveness to be considered sufficient, the result should be in accordance with the hypotheses. In cases where no hypotheses were provided in the article, the review team formulated hypotheses themselves (table 3). ${ }^{14}$ Due to the limited studies concerning PROMs in patients with aSAH, it was not possible to deduce a conclusion on the quality of measurement properties by statistically pooling the results; therefore, we report the best evidence synthesis per measurement property separately. Finally, since there are no quality criteria for interpretability, we present the data in the text.

COSMIN step 3: Assessment of the level of the evidence The quality of the evidence for each PROM was based on the number and quality of the studies using this approach, and summarized for each measurement property based on 
Table 2 Quality criteria for measurement properties

\begin{tabular}{|c|c|c|c|c|c|}
\hline Domain & Measurement property & $\begin{array}{l}\text { Aspect of } \\
\text { a measurement } \\
\text { property }\end{array}$ & Definition & Rating & Quality criteria \\
\hline \multirow[t]{10}{*}{ Reliability } & & & $\begin{array}{l}\text { The degree to which the measurement is free from } \\
\text { measurement error }\end{array}$ & & \\
\hline & Internal consistency & & The degree of interrelatedness among the items & + & $\begin{array}{l}\text { At least low evidence }{ }^{b} \text { for sufficient structural validity }{ }^{c} \text { and } \\
\text { Cronbach alpha(s) } \geq 0.70 \text { for each unidimensional scale or } \\
\text { subscale }^{d}\end{array}$ \\
\hline & & & & $?$ & $\begin{array}{l}\text { Criteria for "At least low evidence }{ }^{\mathrm{b}} \text { for sufficient structural } \\
\text { validity" not met }\end{array}$ \\
\hline & & & & - & $\begin{array}{l}\text { At least low evidence }{ }^{b} \text { for sufficient structural validity }{ }^{c} \text { and } \\
\text { Cronbach alpha(s) }<0.70 \text { for each unidimensional scale or } \\
\text { subscale }^{d}\end{array}$ \\
\hline & Reliability & & $\begin{array}{l}\text { The proportion of the total variance in the } \\
\text { measurements which is due to "true" }{ }^{\prime \prime} \text { differences } \\
\text { between patients }\end{array}$ & + & ICC or weighted kappa $\geq 0.70$ \\
\hline & & & & ? & ICC or weighted kappa not reported \\
\hline & & & & - & ICC or weighted kappa $<0.70$ \\
\hline & Measurement error & & $\begin{array}{l}\text { The systematic and random error of a patient's score, } \\
\text { i.e., not attributed to true changes in the construct to } \\
\text { be measured }\end{array}$ & + & SDC or LOA $<M I C^{C}$ \\
\hline & & & & $?$ & MIC not defined \\
\hline & & & & - & $\mathrm{SDC}$ or $\mathrm{LOA}>\mathrm{MIC}$ \\
\hline \multirow[t]{4}{*}{ Validity } & & & $\begin{array}{l}\text { The degree to which a PROM measures the } \\
\text { construct(s) it purports to measure }\end{array}$ & & \\
\hline & Content validity & & $\begin{array}{l}\text { The degree to which the content of a PROM is an } \\
\text { adequate reflection of the construct to be measured }\end{array}$ & & $\begin{array}{l}\text { Definitions according to a separate rating system and not } \\
\text { included in this supplement }{ }^{17}\end{array}$ \\
\hline & & Face validity & $\begin{array}{l}\text { The degree to which (the items of) a PROM indeed } \\
\text { look as though they are an adequate reflection of the } \\
\text { construct to be measured }\end{array}$ & & \\
\hline & Construct validity & & $\begin{array}{l}\text { The degree to which the scores of a PROM are } \\
\text { consistent with hypotheses (e.g., with regard to } \\
\text { internal relationships, relationships to scores of } \\
\text { other instruments, or differences between relevant } \\
\text { groups) based on the assumption that the PROM } \\
\text { validly measures the construct to be measured }\end{array}$ & & \\
\hline
\end{tabular}


Table 2 Quality criteria for measurement properties (continued)

\begin{tabular}{lll}
\hline & Measurement property & $\begin{array}{l}\text { Aspect of } \\
\text { a measurement } \\
\text { property }\end{array}$
\end{tabular}

The degree to which the scores of a PROM are an adequate reflection of the dimensionality of the construct to be measured
CTT:

CFA: CFI or TLI or comparable measure $>0.95$ or RMSEA $<0.06$ or SRMR $<0.08^{\circ}$

IRT/Rasch:

No violation of unidimensionality. CFI or TLI or comparable measure $>0.95$ or RMSEA $<0.06$ or SRMR $<0.08$

no violation of local independence: residual correlations among the items after controlling for the dominant factor $<0.20$ OR Q3s $<0.37$

and

no violation of monotonicity: adequate looking graphs or item scalability $>0.30$

and

adequate model fit:

IRT: $\chi^{2}>0.01$

Rasch: infit and outfit mean squares $\geq 0.5$ and $\leq 1.5$ or $Z$ standardized values $>-2$ and $<2$

\begin{tabular}{|c|c|c|c|c|}
\hline & & & $?$ & $\begin{array}{l}\text { CTT: Not all information for " }+ \text { " reported } \\
\text { IRT/Rasch: Model fit not reported }\end{array}$ \\
\hline & & & - & Criteria for "+" not met \\
\hline & $\begin{array}{l}\text { Hypothesis testing for } \\
\text { construct validity }\end{array}$ & $\begin{array}{l}\text { The degree to which the scores of a PROM are consistent } \\
\text { with hypotheses based on the assumption that the } \\
\text { PROM validly measures the construct to be measured }\end{array}$ & + & The result is in accordance with the hypothesis ${ }^{g}$ \\
\hline & & & $?$ & No hypothesis defined (by the review team) \\
\hline & & & - & The result is not in accordance with the hypothesis ${ }^{g}$ \\
\hline & $\begin{array}{l}\text { Cross-cultural validity/ } \\
\text { measurement } \\
\text { invariance }\end{array}$ & $\begin{array}{l}\text { The degree to which the performance of the items on } \\
\text { a translated or culturally adapted PROM are an } \\
\text { adequate reflection of the performance of the items } \\
\text { of the original version of the PROM }\end{array}$ & + & $\begin{array}{l}\text { No important differences found between group factors } \\
\text { (such as age, sex, language) in multiple group factor } \\
\text { analysis or no important DIF for group factors (McFadden } \\
R^{2}<0.02 \text { ) }\end{array}$ \\
\hline & & & $?$ & $\begin{array}{l}\text { No multiple group factor analysis or DIF analysis } \\
\text { performed }\end{array}$ \\
\hline & & & - & $\begin{array}{l}\text { Important differences between group factors or DIF was } \\
\text { found }\end{array}$ \\
\hline \multirow[t]{3}{*}{ Criterion validity } & & $\begin{array}{l}\text { The degree to which the scores of a PROM are an } \\
\text { adequate reflection of a gold standard }\end{array}$ & + & Correlation with gold standard $\geq 0.70$ or AUC $\geq 0.70$ \\
\hline & & & $?$ & Not all information for " + " reported \\
\hline & & & - & Correlation with gold standard $<0.70$ or AUC $<0.70$ \\
\hline
\end{tabular}


Table 2 Quality criteria for measurement properties (continued)

\begin{tabular}{|c|c|c|c|c|c|}
\hline Domain & Measurement property & $\begin{array}{l}\text { Aspect of } \\
\text { a measurement } \\
\text { property }\end{array}$ & Definition & Rating & Quality criteria \\
\hline \multirow[t]{4}{*}{ Responsiveness } & & & $\begin{array}{l}\text { The ability of a PROM to detect change over time in } \\
\text { the construct to be measured }\end{array}$ & & \\
\hline & Responsiveness & & $\begin{array}{l}\text { The ability of a PROM to detect change over time in } \\
\text { the construct to be measured }\end{array}$ & + & $\begin{array}{l}\text { The result is in accordance with the hypothesis }{ }^{g} \text { or AUC } \\
\geq 0.70\end{array}$ \\
\hline & & & & ? & No hypothesis defined (by the review team) \\
\hline & & & & - & $\begin{array}{l}\text { The result is not in accordance with the hypothesis }{ }^{g} \text { or AUC } \\
<0.70\end{array}$ \\
\hline Interpretability & & & $\begin{array}{l}\text { Interpretability is the degree to which one can assign } \\
\text { qualitative meaning-i.e., clinical or commonly } \\
\text { understood connotations-to a PROM's quantitative } \\
\text { scores or change in scores }\end{array}$ & & \\
\hline
\end{tabular}

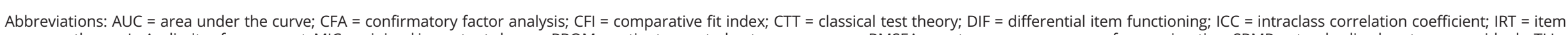

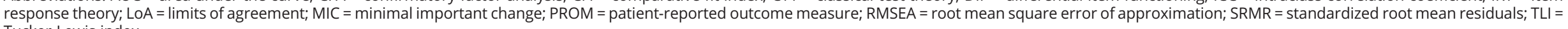
Tucker-Lewis index.

+ = Sufficient; ? = indeterminate; - = insufficient.

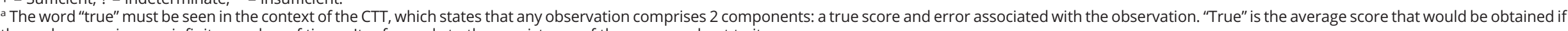
the scale were given an infinite number of times. It refers only to the consistency of the score, and not to its accuracy.

${ }^{\mathrm{b}}$ As defined by grading the evidence according to the GRADE approach.

'This evidence may come from different studies.

"The criteria "Cronbach $a<0.95$ " was deleted, as this is relevant in the development phase of a PROM and not when evaluating an existing PROM.

e To rate the quality of the summary score, the factor structures should be equal across studies.

f Unidimensionality refers to a factor analysis per subscale, while structural validity refers to a factor analysis of a (multidimensional) PROM.

${ }^{\mathrm{g}}$ The results of all studies should be taken together and it should then be decided if $75 \%$ of the results are in accordance with the hypotheses. 
Table 3 Hypotheses about correlations as formulated by the review team

\section{The Subarachnoid Haemorrhage Outcome Tool (SAHOT)}

Hypotheses testing:

The authors formulated their own hypotheses.

Responsiveness:

mRS: we expect the effect size of the SAHOT to be higher than the effect size of the mRS.

Glasgow Outcome Scale Extended: we expect the effect size of the SAHOT to be higher than the effect size of the mRS.

The Stroke-Specific Quality of Life Scale (SS-QoL)

Hypotheses testing:

SF-36: we expect a low correlation with the physical subscale of the SS-QoL, a moderate correlation with the psychosocial subscale of the SS-QoL, and a moderate correlation with the total score of the SS-QoL.

mRS: we expect a moderate correlation with the physical subscale of the SS-QoL, a low correlation with the psychosocial subscale of the SS-QoL, and a low-moderate correlation with the total score of the SS-QoL.

Chinese Lawton Instrumental Activity of Daily Living scale: we expect a moderate correlation with the physical subscale of the SS-QoL, a moderate correlation with the psychosocial subscale of the SS-QoL, and a moderate correlation with the total score of the SS-QoL.

Geriatric Depression Scale: we expect a low correlation with the physical subscale of the SS-QoL, a moderate correlation with the psychosocial subscale of the SS-QoL, and a low-moderate correlation with the total score of the SS-QoL.

Cognitive Failures Questionnaire: we expect a low correlation with the physical subscale of the SS-QoL, a moderate correlation with the psychosocial subscale of the SS-QoL, and a low correlation with the total score of the SS-QoL.

Life Satisfaction questionnaire-9: we expect a low-moderate correlation with the physical subscale of the SS-QoL, a low-moderate correlation with the psychosocial subscale of the SS-QoL, and a low-moderate correlation with the total score of the SS-QoL.

Hospital Anxiety and Depression Scale: we expect a low correlation with the physical subscale of the SS-QoL, a moderate correlation with the psychosocial subscale of the SS-QoL, and a low-moderate correlation with the total score of the SS-QoL.

Glasgow Outcome Scale: we expect a moderate correlation with the physical subscale of the SS-QoL, a low correlation with the psychosocial subscale of the SS-QoL, and a low-moderate correlation with the total score of the SS-QoL.

Responsiveness:

SF-36: we expect a moderate correlation with the total score of the SS-QoL.

The short version of the SS-QoL

Hypotheses testing:

SF-36: we expect a low correlation with the physical subscale of the SS-QoL-sv, a moderate correlation with the psychosocial subscale of the SS-QoL-sv, and a moderate correlation with the total score of the SS-QoL-sV.

mRS: we expect a moderate correlation with the physical subscale of the SS-QoL-sv, a low correlation with the psychosocial subscale of the SS-QoL-sv, and a low-moderate correlation with the total score of the SS-QoL-sv.

Chinese Lawton Instrumental Activity of Daily Living scale: we expect a moderate correlation with the physical subscale of the SS-QoL-sv, a moderate correlation with the psychosocial subscale of the SS-QoL-SV, and a moderate correlation with the total score of the SS-QoL-sV.

Geriatric Depression Scale: we expect a low correlation with the physical subscale of the SS-QoL-sv, a moderate correlation with the psychosocial subscale of the SS-QoL-sv, and a low-moderate correlation with the total score of the SS-QoL-sv.

Montreal Cognitive Assessment: we expect a low correlation with the physical subscale of the SS-QoL-sv, a moderate correlation with the psychosocial subscale of the SS-QoL-sv, and a low correlation with the total score of the SS-QoL-sv.

Abbreviations: $\mathrm{mRS}=$ modified Rankin Scale; SF-36 = Short Form-36.

Definitions: $0.0-0.2$ very low correlation, $0.2-0.4$ low correlation, $0.4-0.6$ moderate correlation, $>0.6$ high correlation.

a modification of the GRADE methodology as outlined in the COSMIN guidelines. ${ }^{16}$ This methodology considers the initial level of evidence to be high, with subsequent downgrading based on the scores for 4 criteria: risk of bias, inconsistencies, imprecision, and indirectness. This results in a high, moderate, low, or very low quality score for the evidence. To evaluate the measurement properties of PROM development and content validity, the overall level of evidence was based on the recently updated COSMIN recommendations. ${ }^{17}$

\section{Data availability}

All data included in this review are available in the articles indicated in table 4. Our search strategy for PubMed is shown in table 1 . The predefined hypotheses of the review team are 
Table 4 Characteristics of the included studies in the systematic review

\begin{tabular}{|c|c|c|c|c|c|}
\hline Author & Year & PROM & Population & $\begin{array}{l}\text { Total no. } \\
\text { of patients }\end{array}$ & $\begin{array}{l}\text { No. of patients } \\
\text { with SAH }\end{array}$ \\
\hline Boosman et al. ${ }^{18}$ & 2009 & SS-QoL & Aneurysmal SAH & 141 & 141 \\
\hline Glick et al. ${ }^{19}$ & 1999 & EQ-5D HUI & Aneurysmal SAH & 561 & 561 \\
\hline Lahiri et al. ${ }^{20}$ & 2016 & $\mathrm{mRS}$ & $\mathrm{SAH}$ & 51 & 51 \\
\hline Pace et al. ${ }^{26}$ & 2018 & SAHOT & Spontaneous SAH & 218 & 218 \\
\hline Post et al. ${ }^{21}$ & 2011 & SS-QoL short version & $\begin{array}{l}\text { Aneurysmal SAH/ischemic } \\
\text { stroke or intracerebral } \\
\text { hemorrhage }\end{array}$ & 345 & 240 \\
\hline Wong et al. ${ }^{23}$ & 2012 & SS-QoL & $\begin{array}{l}\text { Aneurysmal SAH and health } \\
\text { volunteers }\end{array}$ & 104 & 52 \\
\hline Wong et al. ${ }^{24}$ & 2013 & SS-QoL short version & Aneurysmal SAH & 100 & 100 \\
\hline Wong et al. ${ }^{22}$ & 2014 & QOLIBRI-OS & Aneurysmal SAH & 64 & 64 \\
\hline Wong et al. ${ }^{25}$ & 2016 & SS-QoL & Aneurysmal SAH & 56 & 56 \\
\hline
\end{tabular}

Abbreviations: EQ-5D = EuroQol-5D; HUI = Health Utility Index; mRS = modified Rankin Scale; PROM = patient-reported outcome measure; QOLIBRI-OS = Quality of Life after Brain Injury, overall scale; SAH = subarachnoid hemorrhage; SAHOT = Subarachnoid Haemorrhage Outcome Tool; SS-QoL = StrokeSpecific Quality of Life scale.

available in table 3 . The list of excluded studies based on fulltext analysis, including the reason for exclusion, is available on request by investigators. The extracted data are also available on request.

\section{Results}

\section{Selection of validation studies and PROMs}

The search strategy yielded 9,062 articles, of which 6,967 were unique articles. Reference checks resulted in the identification of 8 additional articles. One article published after the date of the initial search was included. After the checks of the titles and abstracts, 47 articles remained. A thorough evaluation of the full texts resulted in a total of 9 articles included in this systematic review. ${ }^{18-26}$ The details of the selection process are shown in the figure. The main reasons for the exclusion of articles were that the questionnaire used in the article was not a PROM or the results for patients with aSAH were not presented separately from those of patients with other (vascular) diseases. The 9 included articles assessed 7 different PROMs: EuroQol 5D (EQ-5D), Health Utility Index (HUI), mRS, Quality of Life after Brain Injury overall scale (QOLIBRI-OS), Subarachnoid Haemorrhage Outcome Tool (SAHOT), Stroke-Specific Quality of Life scale (SS-QoL), and the short version of the SS-QoL. The SAHOT was the only identified PROM specifically developed for SAH. The general characteristics of the studies are presented in table 4 and the characteristics of the PROMs in table 5.

\section{COSMIN step 1: Quality of the included studies}

The methodologic quality of the included studies is presented in table 6 for each questionnaire per measurement property. No assessment of content validity, measurement error, or cross-cultural validity was made in any of the studies, nor was there any reference to previous publications reporting on these measurement properties for the same study population. The majority of the properties were rated as "doubtful" or "inadequate." Flaws in the design of the study or statistical methods of the study contributed 5 times to a final score of "doubtful" and once to an "inadequate" score. These flaws included a lack of a clear description of the applied statistics, no detailed information about which study group was included in the analysis, or other methodologic shortcomings. In 4 articles, it was unclear whether the scale or subscale was unidimensional, resulting in a "doubtful" score. The other causes of a low overall score on a measurement property were an insufficient sample size in factor analysis, scarce information on the measurement properties of the comparator instruments, the inadequate application of statistics, or an unspecified time interval between repeated measures. Criterion validity was only assessed for the 2 articles concerning the short version of the SS-QoL, for which the long version functioned as the gold standard. No gold standards exist for the other PROMs. The score was once "very good," and once "doubtful," because variance was not calculated separately for all domains.

\section{COSMIN steps 2 and 3: Measurement properties and quality of evidence of the PROMs}

The assessment of the measurement properties and the quality of evidence is shown in table 7. The evidence for the measurement properties was scarce due to the small number of studies using these PROMs in patients with aSAH. In addition, only minimal evidence was available regarding the interpretability of the PROMs in the articles, and no formal 


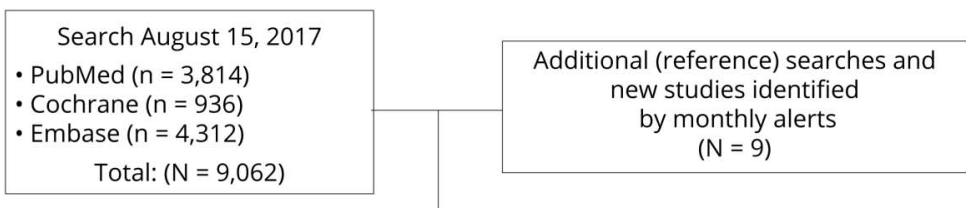

- Duplicates removed $(2,095)$

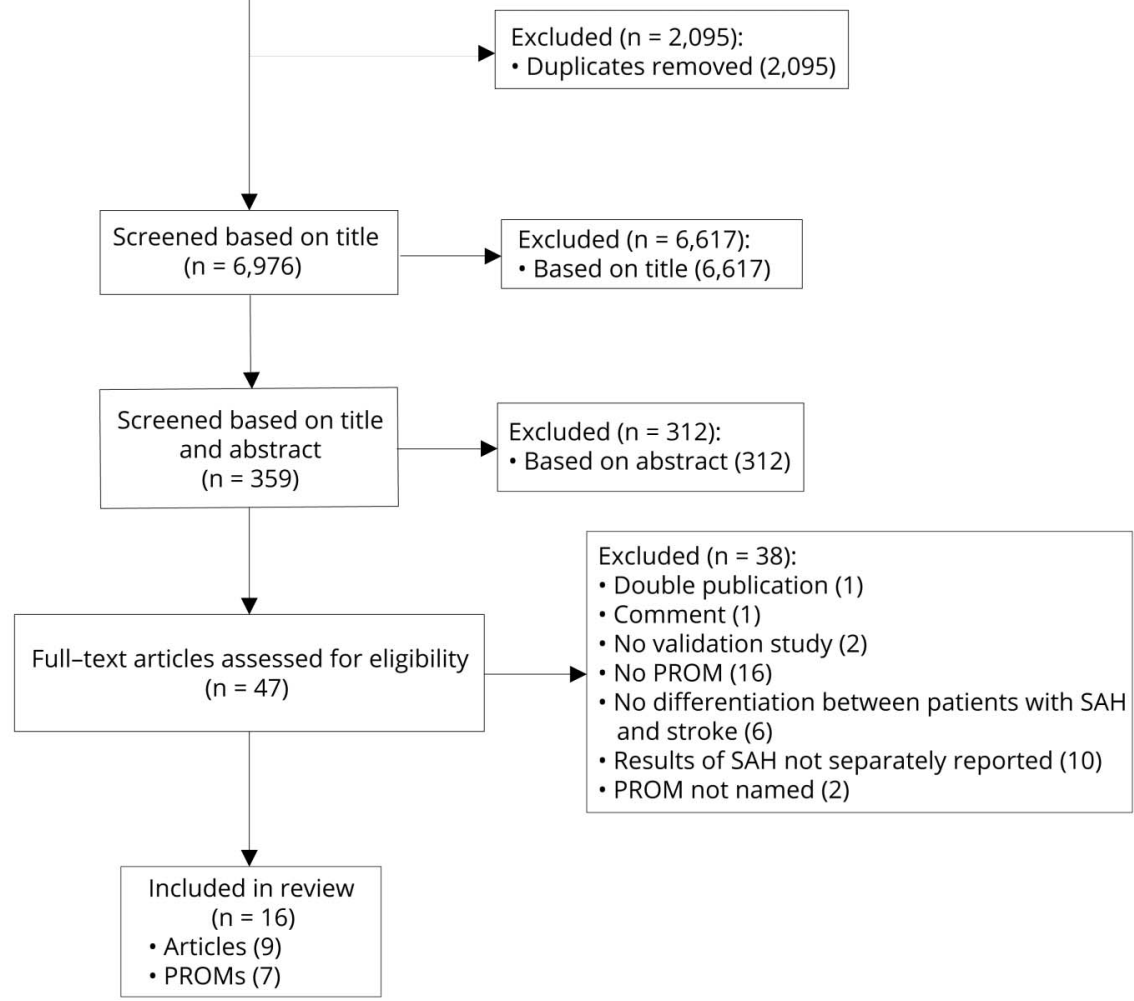

PROM = patient-reported outcome measure, $\mathrm{SAH}=$ subarachnoid hemorrhage.

information on the feasibility of using each PROM for patients with aSAH was provided. The details of the assessed measurement properties of each PROM are outlined separately below.

\section{Modified Rankin Scale}

The mRS is a global disability scale that has an ordinal 7-point scale ranging from no residual symptoms (score of 0 ) to severely disabled (score of 5) or dead (score of 6). ${ }^{27}$ The mRS is an outcome measure that represents mobility and disability in daily and instrumental activities and living arrangements rather than cognitive and social functioning. ${ }^{28}$ The $\mathrm{mRS}$ is an outlier within the included PROMs because it has an incorporated outcome of death; therefore, in essence it is not a PROM. A self-assessed mRS was used in the specific article included in this study, however, which could therefore be considered a PROM.

There is very low evidence for sufficient reliability between 2 different methods of mRS assessment used, namely telephonic assessments using a structured interview and selfreporting obtained via an online survey. The study showed a nonlinear distribution between the mRS scores, with $41 \%-43 \%$ of patients in the highest category and $4 \%$ of patients in the lowest category, indicating a significant ceiling effect. $^{20}$

\section{Quality of Life after Brain Injury overall scale}

The QOLIBRI-OS is a 6-item scale developed to determine the quality of life in patients after brain injury. It includes the domains physical condition, cognition, emotions, function in daily life, personal and social life, and current situation and future prospects. ${ }^{29,30}$ The internal consistency measurement property for the QOLIBRI-OS was rated indeterminate with a very low quality of evidence. No additional information about interpretability was provided.

\section{Subarachnoid Haemorrhage Outcome Tool}

The SAHOT was recently developed as a disease-specific PROM for patients with spontaneous SAH. ${ }^{26}$ The SAHOT 
Table 5 Characteristics of the included patient-reported outcome measures (PROMs) in the systematic review

\begin{tabular}{|c|c|c|c|c|c|}
\hline Name & $\begin{array}{l}\text { Year of } \\
\text { development of } \\
\text { the PROM } \\
\text { (references) }\end{array}$ & $\begin{array}{l}\text { Original } \\
\text { language }\end{array}$ & Domain & No. of items & $\begin{array}{l}\text { Original target } \\
\text { population }\end{array}$ \\
\hline EQ-5D & $1990^{32}$ & English & $\begin{array}{l}\text { Anxiety/depression, global indication of health status, } \\
\text { mobility, pain/discomfort, self-care, usual activities }\end{array}$ & 6 & $\begin{array}{l}\text { General } \\
\text { population }\end{array}$ \\
\hline HUI & $1995^{33}$ & English & $\begin{array}{l}\text { Cognition, emotion, fertility, mobility, pain, self-care, } \\
\text { sensation }\end{array}$ & 7 & $\begin{array}{l}\text { Childhood } \\
\text { cancer }\end{array}$ \\
\hline $\begin{array}{l}\text { mRS } \\
\text { structured } \\
\text { interview }\end{array}$ & $1957^{27}$ & English & Functional outcome & 27 & Stroke \\
\hline $\begin{array}{l}\text { QOLIBRI- } \\
\text { OS }\end{array}$ & $2012^{29,30}$ & $\begin{array}{l}\text { Dutch, English, } \\
\text { Finnish, French, } \\
\text { German, Italian }\end{array}$ & $\begin{array}{l}\text { Cognition, current situation and future prospects, } \\
\text { emotions, function in daily life, personal and social life, } \\
\text { physical condition }\end{array}$ & 6 & $\begin{array}{l}\text { Traumatic brain } \\
\text { injury }\end{array}$ \\
\hline SAHOT & $2018^{26}$ & English & $\begin{array}{l}\text { Cognition, general aspects of daily life, physical } \\
\text { function, behavioral and psychological function }\end{array}$ & 56 & $\begin{array}{l}\text { Spontaneous } \\
\text { subarachnoid } \\
\text { haemorrhage }\end{array}$ \\
\hline SS-QoL & $1999^{31}$ & English & $\begin{array}{l}\text { Energy, family roles, language, mobility, mood, } \\
\text { personality, self-care, social roles, thinking, upper } \\
\text { extremity use, vision, work/productivity }\end{array}$ & 49 & Stroke \\
\hline $\begin{array}{l}\text { SS-QoL } \\
\text { short } \\
\text { version }\end{array}$ & $2011^{21}$ & Dutch, Chinese & $\begin{array}{l}\text { Energy, family roles, language, mobility, mood, } \\
\text { personality, self-care, social roles, thinking, upper } \\
\text { extremity use, vision, work/productivity }\end{array}$ & 12 & Stroke \\
\hline
\end{tabular}

Abbreviations: EQ-5D = EuroQol-5D; HUI = Health Utility Index; mRS = modified Rankin Scale; QOLIBRI = Quality of Life after Brain Injury overall scale; SAHOT = Subarachnoid Haemorrhage Outcome Tool; SS-QoL = Stroke-Specific Quality of Life scale.

was developed in collaboration with patients with aSAH. It consists of the domains cognition, general aspects of daily life, physical function, and behavioral and psychological function. Based on the COSMIN standards, the quality of the PROM development process was "inadequate," since the PROM was adapted after the cognitive interviews took place and the adjusted items were not retested. In addition, the available information about the qualitative methods applied was insufficient. The evidence provided for the PROM development, hypothesis testing for construct validity, and responsiveness was of very low quality, which makes it impossible to draw conclusions about those measurement properties. The low quality of evidence for an indeterminate rating for structural validity and internal consistency was elicited by the lack of detail regarding the Rasch analysis and the absence of evidence for the unidimensionality of the scale. We foresee problems in interpreting the scores, as no direction of change (better or worse) is incorporated in the answer options (no change, some change, large or severe change). Some information about the interpretability is provided; however, this is partially derived from a simulation of a treatment trial and does not represent real-world data since the SAHOT has not been implemented in clinical practice yet. The distribution of the SAHOT has a wide range for each mRS category and all possible categories are scored. There were no floor or ceiling effects. The SAHOT comprises 56 items (table 4). The interpretation of the SAHOT is complex due to the Rasch-based interval analysis, which makes its use less feasible in daily practice. An ordinal scoring version was developed to solve this complexity, but its validity should be evaluated.

\section{Stroke-Specific Quality of Life Scale}

The SS-QoL is a disease-specific PROM that was developed to assess the quality of life in patients after stroke. It contains 49 items and comprises the 12 domains energy, family roles, language, mobility, personality, self-care, social roles, thinking, upper extremity use, vision, and work or productivity. ${ }^{31}$ No conclusions can be drawn regarding the internal consistency, structural validity, and reliability of the SS-QoL, since the overall quality of the evidence is very low. The studies include a Dutch version and a Chinese version of the SS-QoL. The principal component analysis revealed 2 components: physical and psychosocial. In the Dutch version, the physical component includes the following domains: self-care, mobility, upper extremity function, language, vision, and work. The psychosocial component includes thinking, family roles, social roles, personality, mood, and energy. In the Chinese version, language falls in the psychosocial component and the family roles and energy domains fall in the physical component. There is moderate-quality evidence for sufficient hypotheses testing. The responsiveness of the SS-QoL was rated insufficient, with very low evidence quality. The face validity was insufficient, since the answer categories did not fit with all the questions. The distribution of the results showed a ceiling effect for almost all of the 12 domains, except for thinking and energy. Almost none of the patients had the lowest possible score, indicating no floor effects. A ceiling effect of $15 \%$ was 
Table 6 Methodologic quality assessment of the included studies per measurement property per patient-reported outcome measure (PROM)

\begin{tabular}{|c|c|c|c|c|c|c|c|c|c|c|}
\hline $\begin{array}{l}\text { Questionnaire, first } \\
\text { author, and year }\end{array}$ & $\begin{array}{l}\text { PROM } \\
\text { development }\end{array}$ & $\begin{array}{l}\text { Content } \\
\text { validity }\end{array}$ & $\begin{array}{l}\text { Structural } \\
\text { validity }\end{array}$ & $\begin{array}{l}\text { Internal } \\
\text { consistency }\end{array}$ & $\begin{array}{l}\text { Cross-cultural validity/ } \\
\text { measurement invariance }\end{array}$ & Reliability & $\begin{array}{l}\text { Measurement } \\
\text { error }\end{array}$ & $\begin{array}{l}\text { Criterion } \\
\text { validity }\end{array}$ & $\begin{array}{l}\text { Hypotheses testing for } \\
\text { construct validity }\end{array}$ & Responsiveness \\
\hline
\end{tabular}

mRS-SI

Lahiri 2016

D

\section{QOLIBRI-OS}

Wong $2014 \quad$ D

SAHOT

Pace $2018 \quad$ IA D

SS-QoL

\begin{tabular}{lllllll}
\hline Boosman 2010 & IA & VG & D \\
\hline Wong 2012 & IA & D & IA & D
\end{tabular}

Wong 2016

(20)

\section{SS-QoL short version}

\begin{tabular}{llll}
\hline Post 2011 & D & VG \\
\hline Wong 2013 & D & D
\end{tabular}

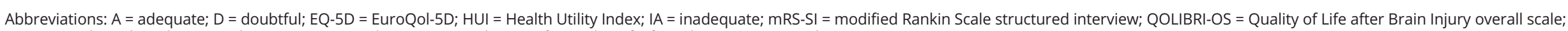
SAHOT = Subarachnoid Haemorrhage Outcome Tool; SS-QoL = Stroke-Specific Quality of Life scale; VG = very good.

Only assessed measurement properties are shown. 
Table 7 Quality of assessed measurement properties per patient-reported outcome measure (PROM) per study and the quality of the evidence per measurement properties

\begin{tabular}{|c|c|c|c|c|c|c|c|}
\hline $\begin{array}{l}\text { Questionnaire, first } \\
\text { author, and year }\end{array}$ & $\begin{array}{l}\text { PROM } \\
\text { development }\end{array}$ & $\begin{array}{l}\text { Structural } \\
\text { validity }\end{array}$ & $\begin{array}{l}\text { Internal } \\
\text { consistency }\end{array}$ & Reliability & $\begin{array}{l}\text { Criterion } \\
\text { validity }\end{array}$ & $\begin{array}{l}\text { Hypotheses } \\
\text { testing }\end{array}$ & Responsiveness \\
\hline \multicolumn{8}{|l|}{ mRS-SI } \\
\hline Lahiri 2016 & & & & + & & & \\
\hline Overall rating & & & & + & & & \\
\hline Quality of evidence & & & & Very low & & & \\
\hline \multicolumn{8}{|l|}{ QOLIBRI-OS } \\
\hline Wong 2014 & & & $?$ & & & & \\
\hline Overall rating & & & $?$ & & & & \\
\hline Quality of evidence & & & Very low & & & & \\
\hline \multicolumn{8}{|l|}{ SAHOT } \\
\hline Pace 2018 & \pm & $?$ & $?$ & & & + & - \\
\hline Overall rating & \pm & $?$ & $?$ & & & + & - \\
\hline Quality of evidence & Very low & Low & Low & & & Very low & Very low \\
\hline \multicolumn{8}{|l|}{ SS-QoL } \\
\hline Boosman 2010 & & + & $?$ & NA & & + & NA \\
\hline Wong 2012 & & + & $?$ & $?$ & & + & NA \\
\hline Wong 2016 & & NA & NA & NA & & NA & - \\
\hline Overall rating & & + & $?$ & $?$ & & + & - \\
\hline Quality of evidence & & Very low & Very low & Very low & & Moderate & Very low \\
\hline \multicolumn{8}{|l|}{ SS-Qol short version } \\
\hline Post 2011 & & & $?$ & & + & NA & \\
\hline Wong 2013 & & & $?$ & & + & + & \\
\hline Overall rating & & & $?$ & & + & + & \\
\hline Quality of evidence & & & Very low & & High & Moderate & \\
\hline
\end{tabular}

Abbreviations: + = Sufficient; ? = indeterminate; - = insufficient; \pm = inconsistent; EQ-5D = EuroQol-5D; HUI = Health Utility Index; mRS-SI = modified Rankin Scale structured interview; NA = no information available; QOLIBRI-OS = Quality of Life after Brain Injury overall scale; SAHOT = Subarachnoid Haemorrhage Outcome Tool; SS-QoL = Stroke-Specific Quality of Life scale.

Only assessed measurement properties are shown.

found for the physical component as a whole, but not for the psychosocial component or the total score on the SS-QoL. With regard to the feasibility of use, the time required for its completion was not described.

\section{Short version of the SS-QoL}

The short version of the SS-QoL was developed since completing the SS-QoL is time-consuming. It consists of the same 12 domains as the SS-QoL with only one question per domain, resulting in a total of 12 items. $^{21}$ The internal consistency score was "doubtful" for this PROM, as no factor analysis was applied. This means that the evidence is of a very low quality and no conclusions can be drawn for the internal consistency of the short version of the SS-QoL. The quality of the evidence regarding a sufficient criterion validity of this
PROM is high, with the long version considered the gold standard. As in the long version, there is moderate quality of evidence for the sufficient hypothesis testing for construct validity in the short SS-QoL. As with the long version, the face validity of the short SS-QoL was insufficient due to the mismatch of the answer categories with some questions.

\section{Generic PROMs}

The EQ-5D is a generic PROM comprising 5 domains: mobility, self-care, usual activities, pain or discomfort, and anxiety or depression. The last question is a visual analogue scale to determine a patient's self-rated general health. ${ }^{32}$ The HUI is health status classification system and consists of the domains sensation, mobility, emotions, cognition, self-care, pain, and fertility. ${ }^{33}$ For the generic EQ-5D and HUI, the articles 
provided no information about the assessment of the measurement properties when using these measures for patients with aSAH. Only a little information regarding the interpretability was available. The visual analogue scores for the EQ-5D instrument were skewed toward higher scores. ${ }^{19}$

\section{Discussion}

In this systematic review, we found limited evidence concerning the assessment of the measurement properties of PROMs when evaluating the outcomes of patients with aSAH. The SS-QoL has been evaluated extensively in patients with aSAH. However, the majority of information regarding the measurement properties is incomplete and the evidence is of a very low quality. The SAHOT was the only PROM specifically developed for patients with aSAH, but the evidence for the measurement properties is of a very low quality. This means it is impossible to draw conclusions about the measurement properties of the SAHOT. None of the PROMs provided evidence for sufficient content validity, which is of utmost importance when using a PROM in clinical practice or research. This lack of assessment of content validity means that all these PROMs might measure items that are not relevant for patients with aSAH, or that items could be interpreted in a different way than originally intended. The current evidence base for selecting a suitable PROM for use with patients with aSAH is therefore insufficient. This result is backed by the results of a recent review about the involvement of patients in the development of PROMs, published in this journal. ${ }^{34} \mathrm{We}$ did not find any high-quality evidence to suggest that the measurement properties are inherently insufficient, however. Therefore, all identified PROMs have the potential to be used for patients with aSAH, but their quality should undergo further assessment. Future research should focus on the assessment of content validity and measurement errors to ensure that the PROM is suitable for use in individual patient care. Given the specific long-term consequences of an aSAH, we consider a disease-specific PROM to be the most appropriate; therefore, the SS-QoL, in long or in short version, seems the most suitable PROM for use with patients with aSAH at this time.

\section{Search strategy and selection of studies and PROMs}

Our systematic review identified a limited number of available validation studies. To a certain extent this is due to the inclusion and exclusion criteria we used. The most important reason for exclusion was that the results for patients with aSAH were not described separately from those of patients with other vascular diseases. An aSAH is a different entity from an ischemic stroke, hemorrhagic stroke, or unruptured aneurysm. Patients with aSAH are generally younger than patients who experience other types of stroke, which results in the higher interference of symptoms in their societal participation and social roles. ${ }^{35}$ Despite this, these vascular diseases are often combined in validation studies of PROMs and conclusions are made for the whole group. We explicitly chose to acknowledge the different disease entities and to focus solely on patients with aSAH. Our search identified 6,976 unique articles on PROs and aSAH, of which just 9 articles were included in the final review. The huge reduction of eligible studies in the selection process was caused by the broad terms we used to cover all relevant PROMs, since no prespecified list of known PROMs was available.

\section{COSMIN guidelines}

Recently, COSMIN addressed the shortcomings in a former checklist by publishing the "Risk of Bias" checklist that was used in this review. ${ }^{14}$ Despite these improvements, some limitations can still be identified in this checklist. The detailed description of comparator instruments is often limited. The comparator instruments used in the included articles are often well known and have been validated for use with various disease entities, but often not for use with patients with aSAH; however, this does not necessarily mean that the methodologic quality of the study is low. In cases where a widely accepted questionnaire, such as the Short Form-36 or EQ-5D, was used as a comparator instrument, we decided to score this item as "adequate." In articles using a questionnaire that is not yet widely accepted, such as the Brain Injury Community Rehabilitation outcome-39 or the Life Satisfaction questionnaire, we scored this item as "doubtful."

Normally, the results of validation studies would be statistically pooled to estimate an average score for the measurement properties. Due to the identification of only one validation study for most PROMs, it was impossible to pool our results. Even for the SS-QoL, for which more studies were available, pooling the domains with an "inadequate" quality score would have resulted in a bias in the pooled results. Other systematic reviews proved that pooling results is inappropriate when different language versions of the PROM are included. ${ }^{36,37}$ This is mainly caused by a nonformalized translation process or the lack of cross-cultural validation. In our review, a Dutch version and a Chinese version of the SS-QoL were included. In all 5 studies concerning the (short) SS-QoL, no assessment of cross-cultural validation was performed. We therefore decided not to pool the results for the SS-QoL.

\section{Quality of measurement properties}

A thorough validation process is important to ensure that the outcomes of a PROM can be relied upon for individual patient care. As mentioned earlier, the evaluation of content validity is vital for the interpretation of the patient outcomes, while reliability, which includes measurement error, is also an important feature. Measurement error is the proportion of the total variance caused by true differences between patients and not by a systematic or random error. In addition, interpretability supplies important information about assigning a qualitative meaning to the scores and teaches us how to interpret the score of an individual patient using a PROM. Only after the assessment of these properties can we say that the PROM properly measures its intended factors and that its 
outcomes can be used to derive clinical meaning. We expected that the investigated PROMs would at least fulfil these requirements; however, this review indicates that further research is required to accomplish this.

The studies included in this review often stated that an assessment of a certain measurement property was performed, when in fact another measurement property was assessed based on the definitions made by the COSMIN panel. ${ }^{15}$ For instance, when criterion validity was mentioned in several studies, actually hypotheses testing for construct validity was assessed. In the assessment of hypotheses testing and responsiveness, hypotheses about the expected correlations were lacking. This shortage in formulated hypotheses is a wellknown problem when reviewing the measurement properties of validation studies ${ }^{14,38}$; therefore, we formulated our own hypotheses for correlations when they were not reported in the included studies (table 3). Sometimes, not all of our hypotheses were met. In these cases, we discussed whether the correlation with the related constructs was higher than the correlation with unrelated constructs. Overall, this resulted in a sufficient rating for all assessments, except for the responsiveness of the SAHOT. ${ }^{26}$ The authors of the article about the SAHOT formulated their own hypotheses with regard to construct validity, and these hypotheses were met; however, we identified some discrepancies in the specified hypotheses. We thought it remarkable to expect a high correlation between the results of the SAHOT and a questionnaire addressing cognitive and emotional problems, but a low correlation with a questionnaire measuring psychosocial functioning. Given that both outcomes are incorporated in the SAHOT and both are well-known health problems for patients after an aSAH, we would have expected a moderate correlation between the results of the SAHOT and both questionnaires. It may therefore be useful to formulate hypotheses for all correlations in a systematic review, regardless of the hypotheses reported in the studies.

\section{Strengths}

This is the first systematic review to evaluate the measurement properties of PROMs in patients with aSAH. We used allembracing search terms that led to a large amount of included titles, which made the search very sensitive. On this ground, we expect to have found all important validation studies concerning PROMs in patients with aSAH. The use of the recently updated COSMIN checklist and the completion of this checklist by 2 independent raters is a strength of the present study. Moreover, in the case of disagreement, we reached a consensus on a final rating by debate and a thorough evaluation of the content and criteria. The reporting of our results is transparent and comprehensive. We illustrate this by presenting our complete search string and a priori formulated hypotheses.

\section{Limitations}

We slightly deviated from the registered study protocol by deleting our second search strategy for the use of PROMs in randomized controlled trials. In 2018, a systematic review was published that covered our second research question and provided an extended overview of the different outcome measures, including PROMs, used in trials. ${ }^{8}$ We believe that our decision to report only the first and main search strategy results in a more easily readable article while still answering our most important research question.

Second, we used the updated COSMIN "Risk of Bias" checklist for the assessment of the quality of the included studies. No research has yet been performed to evaluate the inter-rater agreement and reliability of this updated checklist. The percentage agreement on the original version of the COSMIN checklist was high on an item level, but the reliability, that is, the measure that indicates how well articles can be distinguished from each other based on the given score, was poor for many items. ${ }^{39}$

Another limitation is that our methodology for article selection does not ensure that all PROMs used in literature are included. Due to the high number of studies, we used an initial screening of abstracts, which might have led to missed PROMs that were described in the full-text version of the article. In addition, evidence concerning aspects of the validity of a PROM can be deduced from studies in which the validation of this particular PROM is not the primary objective of the study. Nevertheless, it is not possible to identify all these studies with a systematic literature search without restrictions on the inclusion of PROMs; therefore, we chose not to include these sorts of articles in our systematic review.

There are limited validation studies concerning the measurement properties of PROMs used in patients with aSAH. At least half of the information on the measurement properties is not assessed or the level of evidence is very low. All PROMs identified in this review have the potential to be used for patients with aSAH, but lack a thorough evaluation of the content validity. This means that no conclusions can be drawn about the validity and reliability of the current PROMs used for patients with aSAH. Future research should focus on the assessment of content validity and measurement error to judge the suitability of a PROM for use in individual patient care. Given the specific long-term consequences of aSAH, we consider a disease-specific PROM the most appropriate choice. Our review suggests that the SS-QoL, in long or in short version, is the most suitable PROM currently available.

\section{Acknowledgment}

The authors thank S. Jose, a copyeditor at Radboud University; and A.H.J. Tillema for support with the literature search.

\section{Study funding}

No targeted funding reported. The Article Processing Charge was funded by the Radboud University Medical Center.

\section{Disclosure}

The authors report no disclosures relevant to the manuscript. Go to Neurology.org/N for full disclosures. 


\section{Publication history}

Received by Neurology November 28, 2018. Accepted in final form March 11, 2019.

\section{Appendix Authors}

\begin{tabular}{|c|c|c|c|}
\hline Name & Location & Role & Contribution \\
\hline $\begin{array}{l}\text { Edith } \\
\text { Nobels- } \\
\text { Janssen, } \\
\text { MD }\end{array}$ & $\begin{array}{l}\text { Department of } \\
\text { Neurology, Canisius } \\
\text { Wilhelmina Hospital; } \\
\text { Department of } \\
\text { Neurosurgery, } \\
\text { Radboud University } \\
\text { Medical Center, } \\
\text { Nijmegen, the } \\
\text { Netherlands }\end{array}$ & Author & $\begin{array}{l}\text { Study design, } \\
\text { literature search, } \\
\text { selection of eligible } \\
\text { studies, data analysis, } \\
\text { writing of the first } \\
\text { draft }\end{array}$ \\
\hline $\begin{array}{l}\text { Philip J. } \\
\text { van der } \\
\text { Wees, PhD }\end{array}$ & $\begin{array}{l}\text { Scientific Institute for } \\
\text { Quality of Healthcare } \\
\text { and Department of } \\
\text { Rehabilitation, } \\
\text { Radboud Institute of } \\
\text { Health Sciences, } \\
\text { Radboud University } \\
\text { Medical Center, } \\
\text { Nijmegen, the } \\
\text { Netherlands }\end{array}$ & Author & $\begin{array}{l}\text { Study design, data } \\
\text { analysis, writing of the } \\
\text { first draft, revised the } \\
\text { manuscript for } \\
\text { intellectual content }\end{array}$ \\
\hline $\begin{array}{l}\text { Wim I.M. } \\
\text { Verhagen, } \\
\text { MD }\end{array}$ & $\begin{array}{l}\text { Department of } \\
\text { Neurology, Canisius } \\
\text { Wilhelmina Hospital, } \\
\text { Nijmegen, the } \\
\text { Netherlands }\end{array}$ & Author & $\begin{array}{l}\text { Revised the } \\
\text { manuscript for } \\
\text { intellectual content }\end{array}$ \\
\hline $\begin{array}{l}\text { Gert P. } \\
\text { Westert, } \\
\text { PhD }\end{array}$ & $\begin{array}{l}\text { Scientific Institute for } \\
\text { Quality of Healthcare, } \\
\text { Radboud Institute of } \\
\text { Health Sciences, } \\
\text { Radboud University } \\
\text { Medical Center, } \\
\text { Nijmegen, the } \\
\text { Netherlands }\end{array}$ & Author & $\begin{array}{l}\text { Revised the } \\
\text { manuscript for } \\
\text { intellectual content }\end{array}$ \\
\hline $\begin{array}{l}\text { Ronald } \\
\text { H.M.A. } \\
\text { Bartels, } \\
\text { MD, PhD }\end{array}$ & $\begin{array}{l}\text { Department of } \\
\text { Neurosurgery, } \\
\text { Radboud University } \\
\text { Medical Center, } \\
\text { Nijmegen, the } \\
\text { Netherlands }\end{array}$ & Author & $\begin{array}{l}\text { Revised the } \\
\text { manuscript for } \\
\text { intellectual content }\end{array}$ \\
\hline $\begin{array}{l}\text { Jeroen D. } \\
\text { Boogaarts, } \\
\text { MD, PhD }\end{array}$ & $\begin{array}{l}\text { Department of } \\
\text { Neurosurgery, } \\
\text { Radboud University } \\
\text { Medical Center, } \\
\text { Nijmegen, the } \\
\text { Netherlands }\end{array}$ & Author & $\begin{array}{l}\text { Study design, selection } \\
\text { of eligible studies, } \\
\text { reviewing the first } \\
\text { draft, revised the } \\
\text { manuscript for } \\
\text { intellectual content }\end{array}$ \\
\hline
\end{tabular}

\section{References}

1. Rinkel GJ, Algra A. Long-term outcomes of patients with aneurysmal subarachnoid haemorrhage. Lancet Neurol 2011;10:349-356.

2. Nieuwkamp DJ, Setz LE, Algra A, Linn FH, de Rooij NK, Rinkel GJ. Changes in case fatality of aneurysmal subarachnoid haemorrhage over time, according to age, sex, and region: a meta-analysis. Lancet Neurol 2009;8:635-642.

3. Hackett ML, Anderson CS. Health outcomes 1 year after subarachnoid hemorrhage: an international population-based study: the Australian Cooperative Research on Subarachnoid Hemorrhage Study Group. Neurology 2000;55: 658-662.

4. Al-Khindi T, Macdonald RL, Schweizer TA. Cognitive and functional outcome after aneurysmal subarachnoid hemorrhage. Stroke 2010;41:e519-e536.

5. Kruisheer EM, Huenges Wajer IMC, Visser-Meily JMA, Post MWM. Course of participation after subarachnoid hemorrhage. J Stroke Cerebrovasc Dis 2017;26: 1000-1006.

6. Greenhalgh J, Dalkin S, Gooding K, et al. Functionality and feedback: a realist synthesis of the collation, interpretation and utilisation of patientreported outcome measures data to improve patient care. Health Serv Deliv Res 2017.
7. Passier PE, Visser-Meily JM, Rinkel GJ, Lindeman E, Post MW. Determinants of health-related quality of life after aneurysmal subarachnoid hemorrhage: a systematic review. Qual Life Res 2013;22:1027-1043.

8. Andersen CR, Fitzgerald E, Delaney A, Finfer S. A systematic review of outcome measures employed in aneurysmal subarachnoid hemorrhage (aSAH) clinical research. Neurocrit Care Epub 2018 Jun 27.

9. Nobels-Janssen EvdWP, Westert GP, Bartels RHMA, Boogaarts HD. Patient reported outcome measures after an aneurysmal subarachnoid hemorrhage. In: PROSPERO International Prospective Register of Systematic Reviews. 2017.

10. University of Oxford. PROM Group Construct \& Instrument Type Filters. Available at: cosmin.nl/wp-content/uploads/prom-search-filter-oxford-2010.pdf. Accessed February 19, 2019

11. Terwee CB, Jansma EP, Riphagen II, de Vet HC. Development of a methodological PubMed search filter for finding studies on measurement properties of measurement instruments. Qual Life Res 2009;18:1115-1123.

12. Mokkink LB, Terwee CB, Patrick DL, et al. The COSMIN checklist for assessing the methodological quality of studies on measurement properties of health status measurement instruments: an international Delphi study. Qual Life Res 2010;19: 539-549.

13. Terwee CB, Mokkink LB, Knol DL, Ostelo RW, Bouter LM, de Vet HC. Rating the methodological quality in systematic reviews of studies on measurement properties: a scoring system for the COSMIN checklist. Qual Life Res 2012;21: 651-657.

14. Mokkink LB, de Vet HCW, Prinsen CAC, et al. COSMIN risk of bias checklist for systematic reviews of patient-reported outcome measures. Qual Life Res 2017,27: 1171-1179.

15. Mokkink LB, Terwee CB, Patrick DL, et al. The COSMIN study reached international consensus on taxonomy, terminology, and definitions of measurement properties for health-related patient-reported outcomes. J Clin Epidemiol 2010, 63:737-745.

16. Prinsen CAC, Mokkink LB, Bouter LM, et al. COSMIN guideline for systematic reviews of patient-reported outcome measures. Qual Life Res 2018;27:1147-1157.

17. Terwee CB, Prinsen CAC, Chiarotto A, et al. COSMIN methodology for evaluating the content validity of patient-reported outcome measures: a Delphi study. Qual Life Res 2018;27:1159-1170.

18. Boosman H, Passier PE, Visser-Meily JM, Rinkel GJ, Post MW. Validation of the Stroke Specific Quality of Life scale in patients with aneurysmal subarachnoid haemorrhage. J Neurol Neurosurg Psychiatry 2010;81:485-489.

19. Glick HA, Polsky D, Willke RJ, Schulman KA. A comparison of preference assessmen instruments used in a clinical trial: responses to the visual analog scale from the EuroQol EQ-5D and the Health Utilities Index. Med Decis Making 1999;19: 265-275.

20. Lahiri S, Kamel H, Meyers EE, et al. Patient-powered reporting of modified Rankin Scale outcomes via the Internet. Neurohospitalist 2016;6:11-13.

21. Post MW, Boosman H, van Zandvoort MM, Passier PE, Rinkel GJ, Visser-Meily JM. Development and validation of a short version of the stroke-specific quality of life scale. J Neurol Neurosurg Psychiatry 2011;82:283-286.

22. Wong GK, Lam SW, Ngai K, Wong A, Mok V, Poon WS. Quality of life after brain injury (QOLIBRI) overall scale for patients after aneurysmal subarachnoid hemorrhage. J Clin Neurosci 2014;21:954-956.

23. Wong GK, Lam SW, Ngai K, Wong A, Poon WS, Mok V. Validation of the Strokespecific Quality of Life for patients after aneurysmal subarachnoid hemorrhage and proposed summary subscores. J Neurol Sci 2012;320:97-101.

24. Wong GK, Lam SW, Ngai K, Wong A, Poon WS, Mok V. Development of a short form of Stroke-Specific Quality of Life Scale for patients after aneurysmal subarachnoid hemorrhage. J Neurol Sci 2013;335:204-209.

25. Wong GK, Lee A, Wong A, et al. Clinically important difference of Stroke-Specific Quality of Life Scale for aneurysmal subarachnoid hemorrhage. J Clin Neurosci 2016; 33:209-212.

26. Pace A, Mitchell S, Casselden E, et al. A subarachnoid haemorrhage-specific outcome tool. Brain 2018,141:1111-1121.

27. Rankin J. Cerebral vascular accidents in patients over the age of 60: II: prognosis. Scottish Med J 1957;2:200-215

28. de Haan R, Limburg M, Bossuyt P, van der Meulen J, Aaronson N. The clinical meaning of Rankin 'handicap' grades after stroke. Stroke 1995,26:2027-2030.

29. von Steinbuchel N, Wilson L, Gibbons H, et al. Quality of Life after Brain Injury (QOLIBRI): scale validity and correlates of quality of life. J Neurotrauma 2010,27: $1157-1165$

30. von Steinbuechel N, Wilson L, Gibbons H, et al. QOLIBRI overall scale: a brief index of health-related quality of life after traumatic brain injury. J Neurol Neurosurg Psychiatry 2012,83:1041-1047.

31. Williams LS, Weinberger M, Harris LE, Clark DO, Biller J. Development of a strokespecific quality of life scale. Stroke 1999,30:1362-1369.

32. EuroQol Group. EuroQol: a new facility for the measurement of health-related quality of life. Health Policy 1990,16:199-208.

33. Feeny D, Furlong W, Boyle M, Torrance GW. Multi-attribute health status classification systems: Health Utilities Index. Pharmacoeconomics 1995,7:490-502.

34. Saigle V, Asad S, Presseau J, Chasse M, McIntyre L, English SW. Do patient-reported outcome measures for $\mathrm{SAH}$ include patient, family, and caregiver priorities? A scoping review. Neurology 2019,92:281-295.

35. de Rooij NK, Linn FH, van der Plas JA, Algra A, Rinkel GJ. Incidence of subarachnoid haemorrhage: a systematic review with emphasis on region, age, gender and time trends. J Neurol Neurosurg Psychiatry 2007,78:1365-1372. 
36. Menezes Costa Lda C, Maher CG, McAuley JH, Costa LO. Systematic review of cross-cultural adaptations of McGill Pain Questionnaire reveals a paucity of clinimetric testing. J Clin Epidemiol 2009,62:934-943.

37. Schellingerhout JM, Heymans MW, Verhagen AP, de Vet HC, Koes BW, Terwee CB Measurement properties of translated versions of neck-specific questionnaires: a systematic review. BMC Med Res Methodol 2011,11:87.
38. Abma IL, Rovers M, van der Wees PJ. Appraising convergent validity of patientreported outcome measures in systematic reviews: constructing hypotheses and interpreting outcomes. BMC Res Notes 2016,9:226.

39. Mokkink LB, Terwee CB, Gibbons E, et al. Inter-rater agreement and reliability of the COSMIN (Consensus-based Standards for the selection of health status Measurement Instruments) checklist. BMC Med Res Methodol 2010,10:82.

\section{Now Accepting Applications for Emerging Leaders Program}

Applications are now open for the prestigious Emerging Leaders program, designed to identify, engage, and mentor talent among early-career members interested in future leadership roles within the American Academy of Neurology and the field of neurology. The application deadline is June 17. Learn more and apply at AAN.com/view/ELP.

\section{Share Your Artistic Expressions in Neurology 'Visions'}

AAN members are urged to submit medically or scientifically related artistic images, such as photographs, photomicrographs, and paintings, to the "Visions" section of Neurology ${ }^{\oplus}$. These images are creative in nature, rather than the medically instructive images published in the NeuroImages section. The image or series of up to six images may be black and white or color and must fit into one published journal page. Accompanying description should be 100 words or less; the title should be a maximum of 96 characters including spaces and punctuation.

Please access the Author Center at NPub.org/authors for full submission information.

\section{Sign Up for the AAN's Axon Registry}

The AAN encourages its US members to show their interest in participating in the Axon Registry by signing up today.

Use the Axon Registry to:

- Simplify reporting requirements under MACRA’s Quality Payment Program and avoid penalties while reducing your administrative burden

- Meet your MOC Part IV requirements and waive up to eight credits of Part II Self-Assessment

- Choose from 22 AAN neurology-specific quality measures that fit your practice

- Use data to understand your practice and identify where improvements can be made to patient care

- Manage your patients at a population level; look at a specific group of patients based on conditions, risk factors, demographics or outcome

- Demonstrate your value to payers when negotiating reimbursement

- Enjoy multi-year, fee-free access when you sign the agreements and integrate your EHR with the registry

Learn more at AAN.com/view/Axon and send your questions to registry@aan.com. 


\section{Neurology}

Patient-reported outcome measures in subarachnoid hemorrhage: A systematic review Edith Nobels-Janssen, Philip J. van der Wees, Wim I.M. Verhagen, et al. Neurology 2019;92;1096-1112 Published Online before print May 10, 2019

DOI 10.1212/WNL.0000000000007618

This information is current as of May 10, 2019

Updated Information \&
Services
References
Citations
Subspecialty Collections
Permissions \& Licensing
Reprints

Updated Information \&

References

Citations

Subspecialty Collections

Reprints including high resolution figures, can be found at: http://n.neurology.org/content/92/23/1096.full

This article cites 35 articles, 9 of which you can access for free at: http://n.neurology.org/content/92/23/1096.full\#ref-list-1

This article has been cited by 1 HighWire-hosted articles: http://n.neurology.org/content/92/23/1096.full\#\#otherarticles

This article, along with others on similar topics, appears in the following collection(s):

Clinical trials Systematic review/meta analysis

http://n.neurology.org/cgi/collection/clinical_trials_systematic_review_ meta_analysis

Subarachnoid hemorrhage

http://n.neurology.org/cgi/collection/subarachnoid_hemorrhage

Information about reproducing this article in parts (figures,tables) or in its entirety can be found online at:

http://www.neurology.org/about/about_the_journal\#permissions

Information about ordering reprints can be found online:

http://n.neurology.org/subscribers/advertise

Neurology $\mathbb{B}$ is the official journal of the American Academy of Neurology. Published continuously since 1951, it is now a weekly with 48 issues per year. Copyright Copyright @ 2019 The Author(s). Published by Wolters Kluwer Health, Inc. on behalf of the American Academy of Neurology.. All rights reserved. Print ISSN: 0028-3878. Online ISSN: 1526-632X.

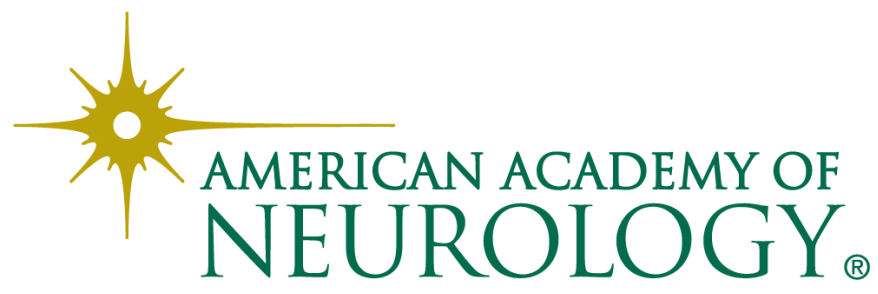

